\title{
PATENTWATCH
}

\section{Look-alike not too alike}

The first in a series of cases brought by the Japanese pharmaceutical company Eisai Co. against 12 generic drug companies accused of selling look-alike generic drugs has been dismissed by a Tokyo District Court. Eisai filed legal action under Japan's Unfair Competition Act claiming that the companies' generic versions of Eisai's gastritis and gastric ulcer medication, teprenone (Selbex) look too similar to their own branded drug. Japanese Unfair Competition Law prohibits several types of unfair competition, including "using an indication of goods which is identical with or similar to another person's identification of goods which is widely recognised among users and thereby causes one person's goods to be confused with another's". Eisai claim that similarities between the press-through pack sheet and the capsule design of generic versions of teprenone and Selbex could pose a risk to medical institutions and patients who might confuse the two products. The claim against Taiyo Yakuhin Co. was rejected by the Tokyo Court but no judgment has yet been made on the 11 other cases.

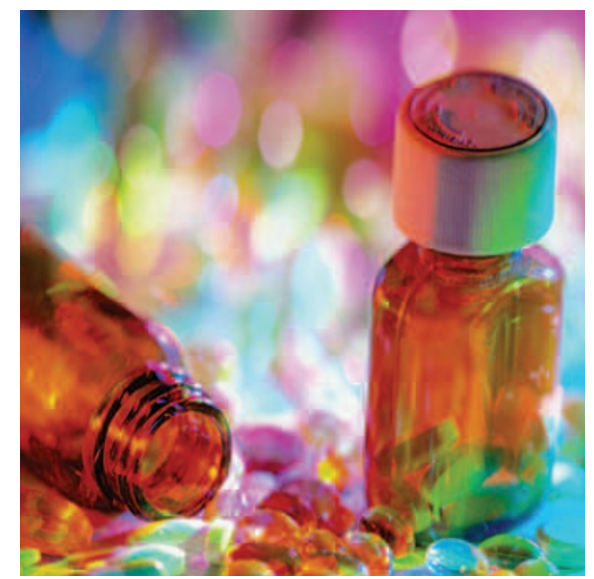

